\title{
Calculation a New Transmission Coefficient of Tunneling for an Arbitrary Potential Barrier and Application to Alpha Decay
}

\author{
Hasan Hüseyin Erbil \\ Physics Department, Faculty of Science, Ege University, Bornova - Izmir, Turkey
}

Email address:

hhuseyin.erbil@gmail.com

To cite this article:

Hasan Hüseyin Erbil. Calculation a New Transmission Coefficient of Tunneling for an Arbitrary Potential Barrier and Application to Alpha Decay. Journal of Photonic Materials and Technology. Vol. 5, No. 2, 2019, pp. 24-31. doi: 10.11648/j.jmpt.20190502.11

Received: January 15, 2019; Accepted: December 23, 2019; Published: December 25, 2019

\begin{abstract}
According to classical physics theories, a moving particle cannot move to an environment with greater potential energy than its total energy during movement. But according to quantum theories, this event is known to be. This event is called tunneling. Tunneling is a probability, and it is measured by a transition coefficient. Correct calculation of this coefficient is very important because very sensitive and important instruments have been developed based on this event, and many events in nature can be explained by tunneling. This coefficient is generally calculated by semi-classical approaches (WKB) and the known formula is an approximate formula. In this paper, the general transmission coefficient of a potential barrier with arbitrary form is calculated by a simple method without any approximation. The results are applied to calculate the half-life values of the nuclei that emit alpha particles. The half-life values obtained from our calculations and the classical method (WKB) have been compared, and it has been found that the new half-life values are exactly consistent with the experimental values.
\end{abstract}

Keywords: Tunneling, Transmission Coefficient, Alpha Decay, Half-Life of Alpha Decay

\section{Introduction}

When a flowing particle or particle current is encountered with a potential energy barrier greater than its total energy, it cannot pass the potential barrier and return to its environment or disappear within the potential according to classical physics. However, the observations indicate that such a particle or particle current may pass the potential barrier. In quantum physics, this phenomenon is called tunneling. This phenomenon cannot be explained according to classical physics theories. One of the greatest achievements of quantum physics theory is that it can explain the tunneling or tunneling event. The probability of passing the potential barrier of the particles is determined by the passing (or transmission) coefficient. This coefficient indicates the possibility of passing the potential barrier of the particle. Where and how this coefficient is used can be found in many publications. It is also a fact that some very sensitive instruments are based on the phenomenon of this formula. This well-known formula is obtained by a semi-classical calculation method called Wentzel-Kramers-Brillouin (WKB) Method in Quantum Mechanics and is an approximate formula as its name suggests. In this paper, a new formula is obtained without any approximation and this formula can be easily applied to any form of potential barrier. This formula is shown to be more accurate and realistic, applying to the alpha decay of some well-known atomic nuclei in nuclear physics. Experimental data were compared with theoretical calculations.

The time-independent radial Schrödinger Equation (SE) in spherical polar coordinates for a particle in a spherical symmetric potential is given as follows:

$$
\frac{d^{2} F(r)}{d r^{2}}+\frac{2 m}{\hbar^{2}}[E-U(r)] F(r)=0
$$

Where $\mathrm{E}$ is the total energy, $\mathrm{U}(\mathrm{r})$ is the effective central potential energy and given as follows:

$$
\mathrm{U}(\mathrm{r})=\mathrm{V}(\mathrm{r})+\frac{\hbar^{2}}{2 \mathrm{~m}} \frac{\ell(\ell+1)}{\mathrm{r}^{2}}
$$


Here $V(r)$ is the central potential. $F(r)$ is the radial part of the wave function $\Psi(r, \theta, \phi)$, namely,

$$
\begin{gathered}
\Psi(r, \theta, \phi)=R(r) Y_{\ell \mu}(\theta, \phi) \\
=\frac{F(r)}{r} Y_{\ell \mu}(\theta, \phi)=\frac{F(r)}{r} \mid \ell j m>
\end{gathered}
$$

Here, $\mathrm{Y}_{\ell \mu}(\theta, \phi)$ is the spherical harmonic function, and $\mid \ell \mathrm{jm}>$ is wave function of total angular momentum. In the previous studies [1], [2], [3], the general solutions of this radial SE have been found. One of these solutions is as follows:

$$
F(r)=A e^{k\left(r-r_{0}\right) \pm i G\left(r-r_{0}\right)}+B e^{-k\left(r-r_{0}\right) \mp i G\left(r-r_{0}\right)}
$$

or

$$
F(r)=A e^{k r \pm i G(r)}+B e^{-k r \mp i G(r)}
$$

Here;

(a) For the case of $\mathrm{E}>\mathrm{U}(\mathrm{r})$;

$$
k=m_{1} \sqrt{-E}, \quad G(r)=m_{1} \int \sqrt{-U(r)} d r
$$

(b) For the case of $\mathrm{E}<\mathrm{U}(\mathrm{r})$;

$$
\begin{gathered}
\mathrm{k}=\mathrm{m}_{1} \sqrt{\mathrm{E}}, \mathrm{G}(\mathrm{r})=\mathrm{m}_{1} \int \sqrt{\mathrm{U}(\mathrm{r})} \mathrm{dr} \\
\mathrm{m}_{1}=\sqrt{2 \mathrm{~m}} / \hbar=\sqrt{2 \mathrm{~m} / \hbar^{2}}, \mathrm{G}(\mathrm{r}) \text { is real function }
\end{gathered}
$$

Here, $m$ mass or reduced mass of particle, and $\hbar=$ $h /(2 \pi), \quad(h$ Planck constant $) . r_{1}$ and $r_{2},\left(r_{2}>r_{1}\right)$ are depending on $\mathrm{E}$ and they are the roots of the equation $\mathrm{E}=$ $\mathrm{U}(\mathrm{r})$. Here we have the following equalities:

$$
\begin{gathered}
\mathrm{r}_{0}=\left(\mathrm{r}_{1}+\mathrm{r}_{2}\right) / 2 ; \mathrm{d}=\mathrm{r}_{2}-\mathrm{r}_{1} ; \\
\mathrm{r}_{1}=\mathrm{r}_{0}-\mathrm{d} / 2 ; \mathrm{r}_{2}=\mathrm{r}_{0}+\mathrm{d} / 2 ;\left(\mathrm{r}_{2}>\mathrm{r}_{1}\right) \\
|\mathrm{E}|=\left|\mathrm{U}\left(\mathrm{r}_{0}-\mathrm{d} / 2\right)\right|=\left|\mathrm{U}\left(\mathrm{r}_{0}+\mathrm{d} / 2\right)\right| \\
2|\mathrm{E}|=\left|\mathrm{U}\left(\mathrm{r}_{0}-\mathrm{d} / 2\right)\right|+\left|\mathrm{U}\left(\mathrm{r}_{0}+\mathrm{d} / 2\right)\right|
\end{gathered}
$$

This solution is similar to the Wentzel-Kramers-Brillouin (WKB) approach but is not exactly the same. There are approximations in the WKB method, but there is no approximation the method that we have given here. This procedure gives exact results. Those who are familiar with the WKB approach can easily see the differences.

In bound states, the normalized wave functions are as follows:

$$
\begin{gathered}
\psi(r)=A \cos [K r] e^{i G(r)} \text { or } \\
\psi(r)=A \cos \left[K\left(r-r_{0}\right)\right] e^{i G\left(r-r_{0}\right)}
\end{gathered}
$$

and

$$
\begin{gathered}
\psi(r)=B \sin [K r] e^{i G(r)} \text { or } \\
\psi(r)=B \sin \left[K\left(r-r_{0}\right)\right] e^{i G\left(r-r_{0}\right)}
\end{gathered}
$$

$$
\begin{aligned}
& A=B=\sqrt{2 / d}=\sqrt{2 K / q} \\
& \mathrm{~K}=\mathrm{m}_{1} \sqrt{|\mathrm{E}|}=\sqrt{\frac{2 \mathrm{~m}}{\hbar^{2}}} \sqrt{|\mathrm{E}|},\left[\mathrm{m}_{1}=\sqrt{\frac{2 \mathrm{~m}}{\hbar^{2}}}\right] \\
& G(r)=m_{1} \int \sqrt{|U(r)|} d r . \\
& K d=q \sqrt{\frac{2 m}{\hbar^{2}}|E| d}=q \\
& |E|=\frac{\hbar^{2}}{2 m} \frac{q^{2}}{d^{2}}=M_{h} \frac{q^{2}}{d^{2}} ;\left[M_{h}=\frac{\hbar^{2}}{2 m}\right]
\end{aligned}
$$

For $\mathrm{q}=2$ ground state (minimum energy of bound states) occurs; for $q=n \pi,(n=1,2,3, \ldots)$ exited states occur.

\section{Calculation of the Transmission Coefficient for an Arbitrary Potential Barrier}

\subsection{Determination of the Wave Functions}

Let us reconsider the solution as follows:

$$
F(r)=A e^{k r \pm i G(r)}+B e^{-k r \mp i G(r)}
$$

Here,

(a) For the case of $\mathrm{E}>\mathrm{U}(\mathrm{r})$;

$$
k=i m_{1} \sqrt{E}, G(r)=i m_{1} \int \sqrt{U(r)} d r
$$

(b) For the case of $\mathrm{E}<\mathrm{U}(\mathrm{r})$;

$$
k=m_{1} \sqrt{E}, G(r)=m_{1} \int \sqrt{U(r)} d r
$$

Let us divide the potential zone into three domains, as seen in Figure 1. In the region I, $\mathrm{E}>\mathrm{U}_{1}$; in the region II, $\mathrm{E}<\mathrm{U}_{2}$ and in the region III, $E>\mathrm{U}_{3}$. Now, consider that a particle with total energy E comes from the left as in Figure 1 and hits the barrier at the point $r_{1}$.

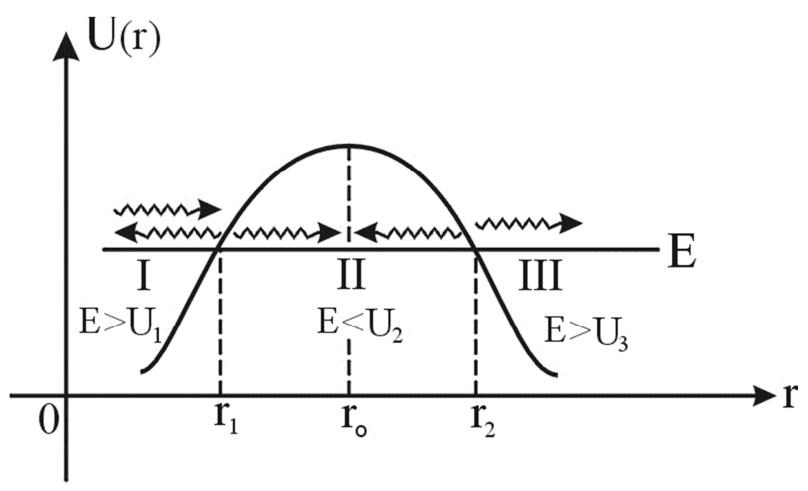

Figure 1. The unbounded state (potential barrier) and tunneling.

According to the functions given in Eq. (4), the wave functions can be obtained for these three regions as follows: 


$$
\begin{gathered}
F_{1}(r)=A_{1} e^{i K r \pm Q_{1}(r)}+B_{1} e^{-i K r \mp Q_{1}(r)} \\
F_{2}(r)=A_{2} e^{K r \mp i Q_{2}(r)}+B_{2} e^{-K r \pm i Q_{2}(r)} \\
F_{3}(r)=A_{3} e^{i K r \pm Q_{3}(r)} \\
K=m_{1} \sqrt{E}, Q_{p}(r)=m_{1} \int \sqrt{U_{p}(r)} d r,(p=1,2,3)
\end{gathered}
$$

In the calculations of the above functions, the fact that the waves travel both from left to right and right to left in the region I and only from left to right in the region III has been taken into account. Since there is no wave coming from right to left in the region III, the coefficient $B_{3}$ must be zero.

\subsection{Calculation of the Transmission Coefficient T}

To calculate the transmission coefficient $\mathrm{T}$, the coefficients $A_{i}$ and $B_{i}$ given in Eq. (5) must be found. In order to find these coefficients, the following boundary conditions are used:

$$
\begin{array}{ll}
\mathrm{F}_{1}\left(\mathrm{r}_{1}\right)=\mathrm{F}_{2}\left(\mathrm{r}_{1}\right) ; \mathrm{F}_{1}^{\prime}\left(\mathrm{r}_{1}\right)=\mathrm{F}_{2}^{\prime}\left(\mathrm{r}_{1}\right) ; \\
\mathrm{F}_{2}\left(\mathrm{r}_{2}\right)=\mathrm{F}_{3}\left(\mathrm{r}_{2}\right) ; \mathrm{F}_{2}^{\prime}\left(\mathrm{r}_{2}\right)=\mathrm{F}_{3}^{\prime}\left(\mathrm{r}_{2}\right) ;
\end{array}
$$

$$
\begin{gathered}
E=U_{1}\left(r_{1}\right)=U_{2}\left(r_{1}\right) ; E=U_{2}\left(r_{2}\right)=U_{3}\left(r_{2}\right) ; m_{1} \sqrt{E}=m_{1} \sqrt{U_{p}\left(r_{1}\right)}=m_{1} \sqrt{U_{p}\left(r_{2}\right)}= \\
K ; m_{1} \sqrt{E}=m_{1} \sqrt{U_{p}\left(r_{1}\right)}=m_{1} \sqrt{U_{p}\left(r_{2}\right)}=K \\
Q_{p}(r)=m_{1} \int \sqrt{U_{p}(r)} d r Q_{p}^{\prime}(r)=m_{1} \sqrt{U_{p}(r)} ; Q_{p}^{\prime}\left(r_{1}\right)=Q_{p}^{\prime}\left(r_{2}\right)=K
\end{gathered}
$$

In the functions given in Equation (5), there are five unknown coefficients. Four of them can be found in terms of $A_{1}$. All of the coefficients have been calculated in this study, but here, only the coefficient $A_{3}$ is sufficient. According to the signs of the exponential terms in Equation (5), two values are found for $A_{3}$.

For the lower part of signs:

$$
A_{3}=\frac{2 \exp \left[(1+i) K r_{1}+(1-i) K r_{2}-Q_{1}\left(r_{1}\right)+i Q_{2}\left(r_{1}\right)+i Q_{2}\left(r_{2}\right)+Q_{3}\left(r_{2}\right)\right]}{\exp \left[2 \mathrm{Kr}_{1}+2 i Q_{2}\left(r_{1}\right)\right]+\exp \left[2 \mathrm{Kr}_{2}+2 i Q_{2}\left(r_{2}\right)\right]} A_{1}
$$

For the upper part of signs:

$$
A_{3}=\frac{2 \exp \left[(1+i) K r_{1}+(1-i) K r_{2}+Q_{1}\left(r_{1}\right)+i Q_{2}\left(r_{1}\right)+i Q_{2}\left(r_{2}\right)-Q_{3}\left(r_{2}\right)\right]}{\exp \left[2 \mathrm{Kr}_{1}+2 i Q_{2}\left(r_{2}\right)\right]+\exp \left[2 \mathrm{Kr}_{2}+2 i Q_{2}\left(r_{1}\right)\right]} A_{1}
$$

The transmission coefficient is defined as follows:

$$
\begin{gathered}
T=\frac{A_{3} A_{3}^{*}}{A_{1} A_{1}^{*}}=\frac{2}{\cosh [2 K d]+\cos [2 \mathrm{P}]} \\
P=Q_{2}\left(r_{2}\right)-Q_{2}\left(r_{1}\right)=\sqrt{\frac{2 m}{\hbar^{2}}} \int_{r_{1}}^{r_{2}} \sqrt{U_{2}(r)} d r \\
Q_{2}(r)=m_{1} \int \sqrt{U_{2}(r)} d r=\sqrt{\frac{2 m}{\hbar^{2}}} \int \sqrt{U_{2}(r)} d r
\end{gathered}
$$

\section{Application to Alpha Decay in Nuclei and Calculation of Half-Life}

\subsection{Calculation of Half-Life Formula}

An $\alpha$-particle is the nucleus of a helium atom. It consists of two protons and two neutrons. In the process of $\alpha$-decay of nuclei, an $\alpha$-particle is assumed to move in a spherical region determined by the daughter nucleus. The central feature of this one-body model is that the $\alpha$-particle is preformed inside the parent nucleus. The theory does not prove that $\alpha$-particle is preformed but it proves that it behaves as if it is [9]. Figure 2 shows a plot, suitable for purposes of the theory, of the potential energy between the $\alpha$-particle and the residual nucleus for various distances between their centers. The horizontal line $E_{\alpha}$ is the disintegration energy. There are three regions of interest. In the spherical region $r<r_{1}$, we are inside the nucleus and speak of a potential well with of depth $-\mathrm{U}_{0}$, where $\mathrm{U}_{0}$ is taken as a positive number. Classically, the $\alpha$-particle can move in this region with a
In Equations (6) and (7), $r_{1}$ and $r_{2}$ are abscises of the points that the particle hits and leaves the potential barrier, respectively.
From the literature [4], [8], the transmission coefficient by the method WKB is known as follows:

$$
\mathrm{T}=\mathrm{e}^{-2 \mathrm{~g}},\left[\mathrm{~g}=\sqrt{\frac{2 \mathrm{~m}}{\hbar^{2}}} \int_{\mathrm{r}_{1}}^{\mathrm{r}_{2}} \sqrt{\mathrm{U}_{2}(\mathrm{r})-\mathrm{E}} \mathrm{dr}\right]
$$

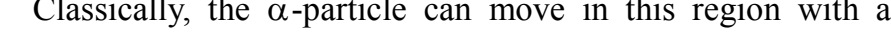


kinetic energy $E_{\alpha}+U_{0}$ but cannot escape from it. The region $r_{1}<r<r_{2}$ forms a potential barrier because here the potential energy is more than the total available energy $E_{\alpha}$. The region $r>r_{2}$ is a classically permitted region outside the barrier. From the classical point of view, an $\alpha$-particle in the spherical potential well would reverse its motion every time it tried to pass beyond $r=r_{1}$ of tunneling through such a barrier. A consistent model for this process assumes that $\alpha$ particle is bounded to the nucleus by a spherical potential well $V_{1}(r)$ or a spherical effective potential well $U_{1}(r)$ and that the $\alpha$-particle is repelled from the residual nucleus by the central Coulomb potential barrier $V_{2}(r)$ or the effective central Coulomb potential barrier $\mathrm{U}_{2}(\mathrm{r})$. The original radioactive nucleus has the charge $\mathrm{Z} \mathrm{e}$ and the $\alpha$-particle has the charge 2e. Thus the Coulomb potential barrier is as follows:

$$
\mathrm{V}_{2}(\mathrm{r})=\frac{2(\mathrm{Z}-2) \mathrm{e}^{2}}{\mathrm{r}}=\frac{\mathrm{c}}{\mathrm{r}},\left[\mathrm{c}=2(\mathrm{Z}-2) \mathrm{e}^{2}\right]
$$

Thus, the corresponding effective potential function is obtained as:

$$
\text { Kinetic Energy }=\text { K. E. }=\frac{1}{2} \mathrm{~m} \mathrm{v}^{2}=\left[\mathrm{E}_{\alpha}-\left(-\left|\mathrm{E}_{0}\right|\right)\right]=\mathrm{E}_{\alpha}+\left|\mathrm{E}_{0}\right|
$$

From Equation (8), the speed of particle is obtained as follows:

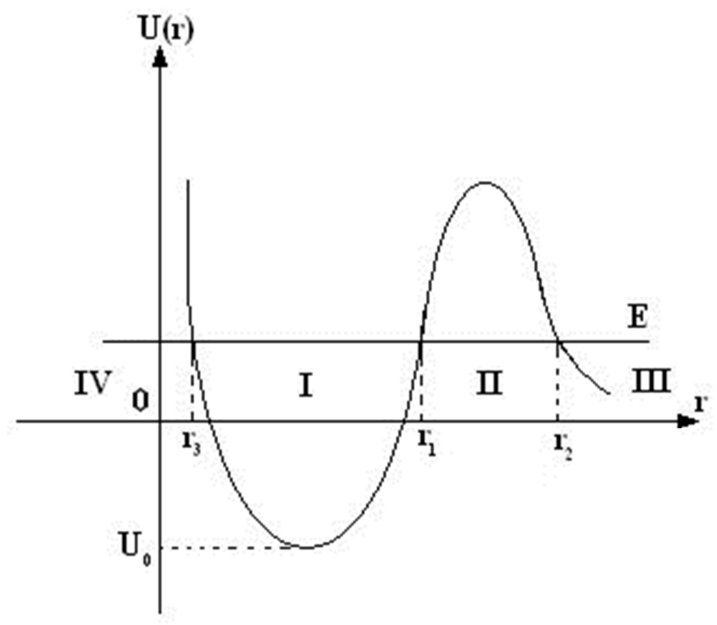

Figure 2. Effective potential function for the $\alpha$-decay process of the nuclei.

$$
v=\sqrt{\frac{2\left(E_{\alpha}+\left|E_{0}\right|\right)}{m}} \text { and } \frac{1}{v}=\sqrt{\frac{m}{2\left(E_{\alpha}+\left|E_{0}\right|\right)}}
$$

If the values of $1 / \mathrm{v}$ and $\lambda=\mathrm{fT}$ are substituted into $t_{1 / 2}=0.693 / \lambda$, then the following formula is obtained:

$$
\begin{aligned}
\mathrm{t}_{1 / 2} & =\frac{0.693}{\lambda}=\frac{0.693}{\mathrm{f} \mathrm{T}}=0.693 \frac{2\left(\mathrm{r}_{1}-\mathrm{r}_{3}\right)}{\mathrm{T}} \frac{1}{\mathrm{v}} \\
& =0.693 \frac{2\left(\mathrm{r}_{1}-\mathrm{r}_{3}\right)}{\mathrm{T}} \sqrt{\frac{\mathrm{m}}{2\left(\mathrm{E}_{\alpha}+\left|\mathrm{E}_{0}\right|\right)}}
\end{aligned}
$$

To simplify the numerical calculations, this formula can be rewritten in the following form:

$$
\mathrm{t}_{1 / 2}=0.693 \frac{2\left(\mathrm{r}_{1}-\mathrm{r}_{3}\right)}{\mathrm{c}} \sqrt{\frac{\mathrm{m} \mathrm{c}^{2}}{2\left(\mathrm{E}_{\alpha}+\left|\mathrm{E}_{0}\right|\right)}} \frac{1}{\mathrm{~T}}
$$

Here, $m=\frac{m_{n} m_{\alpha}}{m_{n}+m_{\alpha}}$ is the reduced mass. $m_{n}$ and $m_{\alpha}$ are the mass of the nucleus and of $\alpha$-particle, respectively.

\subsection{Determination of the Potential Functions}

In our numerical calculations, we have taken the harmonic oscillator type central potential as seen in Figure 3. The central potential parts $V_{1}(r), V_{2}(r), V_{3}(r)$ and the central effective potential parts $U_{1}(r), U_{2}(r), U_{3}(r)$ are as follows:

$$
\begin{gathered}
\mathrm{V}_{1}(\mathrm{r})=-\mathrm{U}_{0}+\mathrm{a} \mathrm{r}^{2} ; \mathrm{U}_{1}(\mathrm{r})=-\mathrm{U}_{0}+\mathrm{ar} \mathrm{r}^{2}+\frac{\mathrm{b}}{\mathrm{r}^{2}} \\
{\left[\mathrm{r}_{3} \leq \mathrm{r} \leq \mathrm{r}_{1}\right] \quad(\text { I region })} \\
\mathrm{V}_{21}(\mathrm{r})=\mathrm{a} \mathrm{r}^{2} ; \mathrm{U}_{21}(\mathrm{r})=\mathrm{a} \mathrm{r}^{2}+\frac{\mathrm{b}}{\mathrm{r}^{2}} ; \\
{\left[\mathrm{r}_{1} \leq \mathrm{r} \leq \mathrm{r}_{\mathrm{m}}\right]\left(\mathrm{II}_{1} \text { region }\right)} \\
\mathrm{V}_{22}(\mathrm{r})=\frac{\mathrm{c}}{\mathrm{r}} ; \mathrm{U}_{22}(\mathrm{r})=\frac{\mathrm{c}}{\mathrm{r}}+\frac{\mathrm{b}}{\mathrm{r}^{2}} ; \\
{\left[\mathrm{r}_{\mathrm{m}} \leq \mathrm{r} \leq \mathrm{r}_{2}\right](\text { II } 2 \text { region })} \\
\mathrm{V}_{3}(\mathrm{r})=\frac{\mathrm{c}}{\mathrm{r}} ; \mathrm{U}_{3}(\mathrm{r})=\frac{\mathrm{c}}{\mathrm{r}}+\frac{\mathrm{b}}{\mathrm{r}^{2}} \\
{\left[\mathrm{r}_{2} \leq \mathrm{r} \leq \infty\right](\text { III region })}
\end{gathered}
$$

Here, $R=R_{0}\left[(A-4)^{1 / 3}+4^{1 / 3}\right]$ is the total rayon of the nucleus and alpha particle. From the solution of the equation $E_{\alpha}=U_{1}(r)=-U_{0}+a r^{2}+\frac{b}{r^{2}}$, we can obtain as follows: 


$$
\begin{aligned}
& r_{1}=\sqrt{\frac{\left(E_{\alpha}+U_{0}\right)+\sqrt{\left(E_{\alpha}+U_{0}\right)^{2}-4 a b}}{2 a}} \\
& r_{3}=\sqrt{\frac{\left(E_{\alpha}+U_{0}\right)-\sqrt{\left(E_{\alpha}+U_{0}\right)^{2}-4 a b}}{2 a}}
\end{aligned}
$$

From the solution of the equation $E_{\alpha}=U_{22}(r)=\frac{c}{r}+\frac{b}{r^{2}}$; we obtain $r_{2}=\frac{c+\sqrt{c^{2}+4 b E_{\alpha}}}{2 E_{\alpha}}$. From the solution of the equation $E_{0}=U_{1}(r)=-U_{0}+a r^{2}+\frac{b}{r^{2}}$, we obtain as follows:

$$
\begin{gathered}
r_{11}=\sqrt{\frac{\left(E_{0}+U_{0}\right)-\sqrt{\left(E_{0}+U_{0}\right)^{2}-4 a b}}{2 a}} \\
r_{12}=\sqrt{\frac{\left(E_{0}+U_{0}\right)+\sqrt{\left(E_{0}+U_{0}\right)^{2}-4 a b}}{2 a}} \\
d_{0}=r_{12}-r_{11} ; d=r_{2}-r_{1}
\end{gathered}
$$

From the solution of the equation

$$
E_{0}=-\frac{\hbar^{2}}{2 m} \frac{q^{2}}{d_{0}^{2}}=-\frac{\hbar^{2}}{2 m} \frac{2^{2}}{d_{0}^{2}}=-\frac{2 \hbar^{2}}{m d_{0}^{2}}
$$

We obtain the ground state energy as follows:

$$
E_{0}=\sqrt{a b}-\frac{1}{2}\left[U_{0}+\sqrt{4 a b-\frac{8 a \hbar^{2}}{m}-4 \sqrt{a b} U_{0}+U_{0}^{2}}\right]
$$

With these grandeurs the coefficients of transmission are written as follows:

$$
\begin{aligned}
& \mathrm{T}_{\mathrm{wkb}}=\mathrm{e}^{-2 \mathrm{P}_{\mathrm{wkb}}} \\
& \mathrm{P}_{\mathrm{wkb}}=\sqrt{\frac{2 \mathrm{~m}}{\hbar^{2}}}\left(\int_{\mathrm{r}_{1}}^{\mathrm{r}_{\mathrm{m}}} \sqrt{\mathrm{U}_{21}(\mathrm{r})-\mathrm{E}_{\alpha}} \mathrm{dr}\right) \\
& +\int_{r_{m}}^{r_{2}} \sqrt{U_{22}(r)-E_{\alpha}} d r \\
& \mathrm{~T}_{\text {new }}=\frac{2}{\cosh [2 \mathrm{Kd}]+\cos \left[2\left\{\mathrm{Q}_{2}\left(\mathrm{r}_{2}\right)-\mathrm{Q}_{2}\left(\mathrm{r}_{1}\right)\right\}\right]} \\
& \mathrm{T}_{\text {new }}=\frac{2}{\cosh [2 \mathrm{Kd}]+\cos \left[2 \mathrm{P}_{\text {new }}\right]} \\
& P_{\text {new }}=\sqrt{\frac{2 \mathrm{~m}}{\hbar^{2}}}\left(\int_{\mathrm{r}_{1}}^{\mathrm{r}_{\mathrm{m}}} \sqrt{\mathrm{U}_{21}(\mathrm{r})} \mathrm{dr}+\int_{\mathrm{r}_{\mathrm{m}}}^{\mathrm{r}_{2}} \sqrt{\mathrm{U}_{22}(\mathrm{r})} \mathrm{dr}\right) \\
& \mathrm{t}_{1 / 2}^{\mathrm{wkb}}=0.693 \frac{2\left(\mathrm{r}_{1}-\mathrm{r}_{3}\right)}{\mathrm{c}} \sqrt{\frac{\mathrm{mc}^{2}}{2\left(\mathrm{E}_{\alpha}-\mathrm{E}_{0}\right)}} \frac{1}{\mathrm{~T}_{\mathrm{wkb}}}
\end{aligned}
$$

$$
\begin{aligned}
& \mathrm{t}_{1 / 2}^{\mathrm{wkb}}=0.693 \frac{2\left(\mathrm{r}_{1}-\mathrm{r}_{3}\right)}{\mathrm{c}} \sqrt{\frac{\mathrm{m} \mathrm{c}^{2}}{2\left(\mathrm{E}_{\alpha}+\left|\mathrm{E}_{0}\right|\right.}} \frac{1}{\mathrm{~T}_{\mathrm{wkb}}} \\
& \mathrm{t}_{1 / 2}^{\text {new }}=0.693 \frac{2\left(\mathrm{r}_{1}-\mathrm{r}_{3}\right)}{\mathrm{c}} \sqrt{\frac{\mathrm{m} \mathrm{c}^{2}}{2\left(\mathrm{E}_{\alpha}-\mathrm{E}_{0}\right)}} \frac{1}{\mathrm{~T}_{\text {new }}} \\
& \mathrm{t}_{1 / 2}^{\text {new }}=0.693 \frac{2\left(\mathrm{r}_{1}-\mathrm{r}_{3}\right)}{\mathrm{c}} \sqrt{\frac{\mathrm{mc}^{2}}{2\left(\mathrm{E}_{\alpha}+\left|\mathrm{E}_{0}\right|\right)}} \frac{1}{\mathrm{~T}_{\text {new }}}
\end{aligned}
$$

The parameters a and $r_{m}$ in potentials can be calculated. To calculate the parameter $a$, the following equation is used:

$$
\mathrm{U}_{1}(\mathrm{r})=-\mathrm{U}_{0}+\mathrm{a} \mathrm{r}^{2}+\frac{\mathrm{b}}{\mathrm{r}^{2}}=0
$$

The roots of this equation are found as follows:

$$
\mathrm{r}_{1}^{\prime}=\sqrt{\frac{\mathrm{U}_{0}+\sqrt{\mathrm{U}_{0}^{2}-4 \mathrm{ab}}}{2 \mathrm{a}}} ; r_{3}^{\prime}=\sqrt{\frac{\mathrm{U}_{0}-\sqrt{\mathrm{U}_{0}^{2}-4 \mathrm{ab}}}{2 \mathrm{a}}}
$$

As it can be seen in Figure 3, the $r_{1}^{\prime}$ can be taken as sum of the radii of the nucleus and the alpha particle. That is, since the radius of the alpha particle is $R_{\alpha}=R_{0} 4^{1 / 3}$ and the radius of the nucleus is $\mathrm{R}_{\mathrm{N}}=\mathrm{R}_{0}(\mathrm{~A}-4)^{1 / 3}$, the total radius is [9] :

$$
R_{c}=R_{\alpha}+R_{N}=R_{0}\left[4^{1 / 3}+(A-4)^{1 / 3}\right]
$$

Thus it can be taken as follows:

$$
\left(\mathrm{r}_{1}^{\prime}\right)^{2}=\mathrm{R}_{\mathrm{c}}^{2}=\left[\mathrm{U}_{0}+\sqrt{\mathrm{U}_{0}^{2}-4 \mathrm{ab}}\right] /(2 \mathrm{a})
$$

From this equation, the value of $\mathrm{a}$ is obtained as:

$$
\mathrm{a}=\frac{\mathrm{U}_{0}}{\mathrm{R}_{\mathrm{c}}^{2}}-\frac{\mathrm{b}}{\mathrm{R}_{\mathrm{c}}^{4}}=\frac{\mathrm{U}_{0} \mathrm{R}_{\mathrm{c}}^{2}-\mathrm{b}}{\mathrm{R}_{\mathrm{c}}^{4}}
$$

To calculate the parameter $r_{m}$, the equation $U_{1}(r)=$ $\mathrm{U}_{22}(\mathrm{r})$ is used and the resolution of this equation gives:

$$
\begin{aligned}
& r_{m}=\frac{2 \sqrt[3]{3} a U_{0}+\sqrt[3]{2} x}{6^{2 / 3} a x} \\
& X=\left[9 a^{2} c+\sqrt{3 a^{3}\left(27 a c^{2}-4 U_{0}^{3}\right)}\right]^{2 / 3}
\end{aligned}
$$

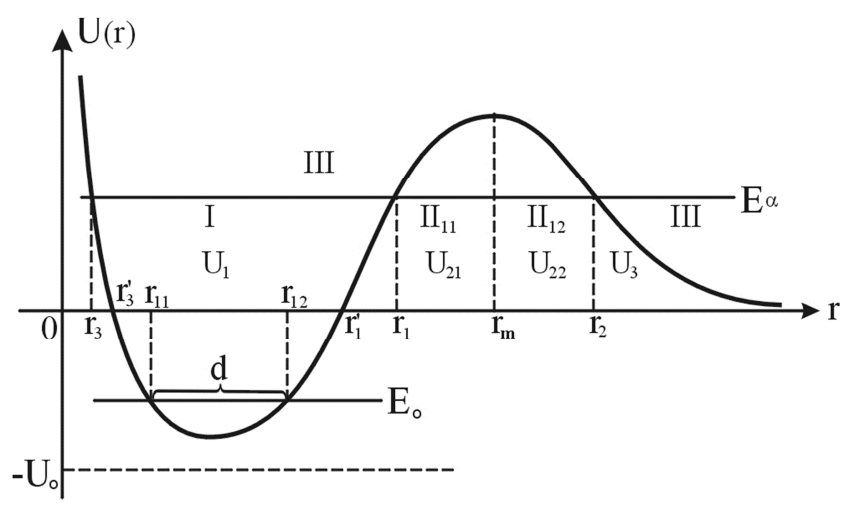

Figure 3. Central harmonic oscillator type effective potential. 
Therefore, the potential depends only on $R_{0}$ and $U_{0}$ parameters, which simplifies the numerical calculations.

\subsection{Numerical Calculations}

To calculate the transmission coefficient $\mathrm{T}$, (or barrier penetration probability), Equations (10) and (11) have been used, and the half-life values, Equations (12) and (13) have been used. The experimental half-life values of the nuclei were taken from [10]. Calculations were made for twenty nuclei and the results are visible in Tables 1-3. In these tables, the half-life values calculated from the new formula and WKB formula are compared with the experimental results. For $\mathrm{R}_{0}$ parameter 1.20 (table 1), 1.21 (table 2) and 1.22 (table 3 ) values have been taken. For each $\mathrm{R}_{0}$ value; firstly, $\mathrm{U}_{0}$ values were changed the interval $5-50 \mathrm{MeV}$ by step 0.001 until $\mathrm{t}_{1 / 2}^{\text {new }} / \mathrm{t}_{1 / 2}^{\text {exp }}$ value is between 0.999 and 1.001 , and one $U_{00}$ value was found. Secondly, $U_{0}$ values were changed between $\left(\mathrm{U}_{00}-1\right)$ and $\left(\mathrm{U}_{00}+1\right)$ by step 0.00001 until the values of $t_{1 / 2}^{\text {new }} / t_{1 / 2}^{\text {exp }}$ is equal to 1 or close to 1 , and thus the best $\mathrm{U}_{0}$ value was found. We have taken calculated values a and $r_{m}$ parameters given Equations (15) and (16) for $U_{0}$ parameters. The half-life values calculated from the new formula and WKB formula are compared with the experimental results. It has seen in the tables that $t_{1 / 2}^{\text {new }}$ values have better results than $t_{1 / 2}^{\mathrm{WKB}}$ values. In all the tables, it can be seen that the new formula is more appropriate than classical formula (WKB). Tables show that the new formula gives very good results with the experiment.

In these tables; first column is nucleus; second column is the experimental energy value of the alpha particle; third and fourth columns $\left(\mathrm{I}_{\mathrm{i}}^{\pi_{\mathrm{i}}}\right.$ and $\left.\mathrm{I}_{\mathrm{f}}^{\pi_{\mathrm{f}}}\right)$ are the initial and final state spins (parity) of the nucleus, respectively. Fifth column $\left(\ell_{\alpha}\right)$ is the orbital angular momentum of the alpha particle; sixth column is the experimental value of the half-life of the nucleus; the seventh column is the most value of the parameter $\mathrm{U}_{0}$; eighth and ninth columns are the WKB and new values of the half-life of the nucleus, respectively; tenth and eleventh columns are the ratios of half-lives. In these tables: y year; d day; h hour; m minute; s second.

Table 1. Comparison of the experimental half-life values and the results calculated using the new and WKB formulas with the harmonic oscillator type well potential for the parameter $R_{0}=1.20 \mathrm{fm}$.

\begin{tabular}{|c|c|c|c|c|c|c|c|c|c|c|}
\hline${ }_{\mathbf{Z}}^{\mathrm{A}} \mathbf{X}$ & $\mathbf{E}_{\alpha}(\mathbf{M e V})$ & $I_{i}^{\pi_{i}}$ & $I_{f}^{\pi_{f}}$ & $\boldsymbol{\ell}_{\alpha}$ & $t_{1 / 2}^{\exp }$ & $\mathrm{U}_{\mathbf{0}}(\mathrm{MeV})$ & $t_{1 / 2}^{w k b}$ & $t_{1 / 2}^{\text {new }}$ & $t_{1 / 2}^{w k b} / t_{1 / 2}^{\exp }$ & $\mathrm{t}_{1 / 2}^{\text {new }} / \mathrm{t}_{1 / 2}^{\exp }$ \\
\hline${ }_{84}^{208} \mathrm{Po}$ & 5.2155 & $0^{+}$ & $0^{+}$ & 0 & $2.898 \mathrm{y}$ & 13.8722 & $0.00100 \mathrm{y}$ & $2.898 \mathrm{y}$ & 0.00034 & 1 \\
\hline${ }_{84}^{210} \mathrm{Po}$ & 5.4075 & $0^{+}$ & $0^{+}$ & 0 & $138.376 \mathrm{~d}$ & 14.4730 & $0.03565 \mathrm{~d}$ & $138.376 \mathrm{~d}$ & 0.00026 & 1 \\
\hline${ }_{86}^{210} \mathrm{Rn}$ & 6.1585 & $0^{+}$ & $0^{+}$ & 0 & $2.40 \mathrm{~h}$ & 8.84247 & $0.00001 \mathrm{~h}$ & $2.40 \mathrm{~h}$ & $5.84254 * 10^{-6}$ & 1 \\
\hline${ }_{86}^{212} \mathrm{Rn}$ & 6.3850 & $0^{+}$ & $0^{+}$ & 0 & $23.9 \mathrm{~m}$ & 9.67596 & $0.00017 \mathrm{~m}$ & $23.9 \mathrm{~m}$ & $6.91599 * 10^{-6}$ & 1 \\
\hline${ }_{86}^{218} \mathrm{Rn}$ & 7.2630 & $0^{+}$ & $0^{+}$ & 0 & $0.035 \mathrm{~s}$ & 6.31225 & $2.56933 * 10^{-8} \mathrm{~s}$ & $0.0350004 \mathrm{~s}$ & $7.33105 * 10^{-7}$ & 1.00001 \\
\hline${ }_{86}^{222} \mathrm{Rn}$ & 5.5903 & $0^{+}$ & $0^{+}$ & 0 & $3.8235 \mathrm{~d}$ & 6.01465 & $4.89374 * 10^{-6} \mathrm{~d}$ & $3.82353 \mathrm{~d}$ & $1.27991 * 10^{-6}$ & 1.00001 \\
\hline${ }_{88}^{222} \mathrm{Ra}$ & 6.6810 & $0^{+}$ & $0^{+}$ & 0 & $38.00 \mathrm{~s}$ & 6.26453 & $0.00002 \mathrm{~s}$ & $38.0003 \mathrm{~s}$ & $5.44108 * 10^{-7}$ & 1.00001 \\
\hline${ }_{90}^{228} \mathrm{Th}$ & 5.5201 & $0^{+}$ & $0^{+}$ & 0 & $1.9116 \mathrm{y}$ & 6.36177 & $2.82674 * 10^{-6} \mathrm{y}$ & $1.91161 \mathrm{y}$ & $1.47873 * 10^{-6}$ & 1 \\
\hline${ }_{90}^{230} \mathrm{Th}$ & 4.7700 & $0^{+}$ & $0^{+}$ & 0 & $75380 y$ & 8.11483 & $3.42796 \mathrm{y}$ & $75380.2 \mathrm{y}$ & 0.00005 & 1 \\
\hline${ }_{90}^{232} \mathrm{Th}$ & 4.0828 & $0^{+}$ & $0^{+}$ & 0 & $1.405 * 10^{10} \mathrm{y}$ & 25.48980 & $6.73357 * 10^{9} \mathrm{y}$ & $1.405 * 10^{10} \mathrm{y}$ & 0.47926 & 1 \\
\hline${ }_{92}^{234} \mathrm{U}$ & 4.8585 & $0^{+}$ & $0^{+}$ & 0 & $2.455 * 10^{5} \mathrm{y}$ & 8.58300 & $12.3123 \mathrm{y}$ & $245501 \mathrm{y}$ & 0.00005 & 1 \\
\hline${ }_{92}^{236} \mathrm{U}$ & 4.5720 & $0^{+}$ & $0^{+}$ & 0 & $2.342 * 10^{7} \mathrm{y}$ & 10.38600 & $11487.8 \mathrm{y}$ & $2.342 * 10^{7} \mathrm{y}$ & 0.00049 & 1 \\
\hline${ }_{94}^{238} \mathrm{Pu}$ & 5.5932 & $0^{+}$ & $0^{+}$ & 0 & $87.7 \mathrm{y}$ & 7.29414 & $0.00021 \mathrm{y}$ & 87.7005 y & $2.34612 * 10^{-6}$ & 1.00001 \\
\hline${ }_{94}^{240} \mathrm{Pu}$ & 5.2558 & $0^{+}$ & $0^{+}$ & 0 & $6563 \mathrm{y}$ & 7.60665 & $0.04275 \mathrm{y}$ & $6563.01 \mathrm{y}$ & $6.51417 * 10^{-6}$ & 1 \\
\hline${ }_{96}^{248} \mathrm{Cm}$ & 5.1617 & $0^{+}$ & $0^{+}$ & 0 & $3.40 * 10^{5} \mathrm{y}$ & 9.08573 & $8.83161 \mathrm{y}$ & $340001 \mathrm{y}$ & 0.00003 & 1 \\
\hline${ }_{98}^{252} \mathrm{Cf}$ & 6.2169 & $0^{+}$ & $0^{+}$ & 0 & $2.645 \mathrm{y}$ & 7.16167 & $1.35978 * 10^{-6} \mathrm{y}$ & $2.645 \mathrm{y}$ & $5.14094 * 10^{-7}$ & 1 \\
\hline${ }_{84}^{209} \mathrm{Po}$ & 4.9792 & $1 / 2^{-}$ & $5 / 2^{-}$ & 2 & $102 y$ & 20.2712 & $0.45071 \mathrm{y}$ & $102 y$ & 0.00442 & 1 \\
\hline${ }_{84}^{211} \mathrm{Po}$ & 7.5945 & $9 / 2^{+}$ & $1 / 2^{-}$ & 5 & $0.516 \mathrm{~s}$ & 20.0278 & $0.00004 \mathrm{~s}$ & $0.516001 \mathrm{~s}$ & 0.00009 & 1 \\
\hline${ }_{85}^{212} \mathrm{At}$ & 7.8289 & $1^{-}$ & $5^{+}$ & 5 & $0.314 \mathrm{~s}$ & 21.3994 & $0.00003 \mathrm{~s}$ & $0.314 \mathrm{~s}$ & 0.00009 & 1 \\
\hline${ }_{90}^{229} \mathrm{Th}$ & 5.1676 & $5 / 2^{+}$ & $1 / 2^{+}$ & 2 & $7340 y$ & 23.5966 & $41.1564 \mathrm{y}$ & $7340 y$ & 0.00561 & 1 \\
\hline${ }_{92}^{233} \mathrm{U}$ & 4.9086 & $5 / 2^{+}$ & $5 / 2^{+}$ & 2 & $1.592 * 10^{5} \mathrm{y}$ & 9.16673 & $10.5838 \mathrm{y}$ & $1.592 * 10^{5} \mathrm{y}$ & 0.00007 & 1 \\
\hline${ }_{93}^{237} \mathrm{~Np}$ & 4.9591 & $5 / 2^{+}$ & $3 / 2^{-}$ & 1 & $2.144 * 10^{6} y$ & 25.8548 & $36342.8 \mathrm{y}$ & $2.144 * 10^{6} y$ & 0.01695 & 1 \\
\hline${ }_{94}^{239} \mathrm{Pu}$ & 5.2445 & $1 / 2^{+}$ & $7 / 2^{-}$ & 3 & $24110 y$ & 10.1464 & $1.12369 \mathrm{y}$ & $24110 y$ & 0.00005 & 1 \\
\hline${ }_{95}^{241} \mathrm{Am}$ & 5.6378 & $5 / 2^{-}$ & $5 / 2^{+}$ & 1 & $432.2 \mathrm{y}$ & 9.39811 & $0.00446 \mathrm{y}$ & $432.201 \mathrm{y}$ & 0.00001 & 1 \\
\hline${ }_{95}^{243} \mathrm{Am}$ & 5.4381 & $5 / 2^{-}$ & $5 / 2^{+}$ & 1 & $7370 \mathrm{y}$ & 10.7484 & $0.28364 \mathrm{y}$ & $7370 y$ & 0.00004 & 1 \\
\hline${ }_{97}^{247} \mathrm{Bk}$ & 5.8890 & $3 / 2^{-}$ & $5 / 2^{-}$ & 2 & $1380 \mathrm{y}$ & 16.8160 & $0.24761 \mathrm{y}$ & $1380 \mathrm{y}$ & 0.00018 & 1 \\
\hline${ }_{98}^{251} \mathrm{Cf}$ & 6.1758 & $1 / 2^{+}$ & $9 / 2^{-}$ & 5 & $898 \mathrm{y}$ & 24.8043 & $1.02889 \mathrm{y}$ & $898.001 \mathrm{y}$ & 0.00115 & 1 \\
\hline
\end{tabular}

Table 2. Comparison of the experimental half-life values and the results calculated using the new and WKB formulas with the harmonic oscillator type well potential for the parameter $R_{0}=1.21 \mathrm{fm}$.

\begin{tabular}{|c|c|c|c|c|c|c|c|c|c|c|}
\hline${ }_{Z}^{A} \mathbf{X}$ & $\mathbf{E}_{\alpha}(\mathbf{M e V})$ & $I_{i}^{\pi_{i}}$ & $I_{f}^{\pi_{f}}$ & $\ell_{\alpha}$ & $t_{1 / 2}^{\exp }$ & $\mathbf{U}_{\mathbf{0}}(\mathrm{MeV})$ & $t_{1 / 2}^{w k b}$ & $t_{1 / 2}^{\text {new }}$ & $t_{1 / 2}^{w k b} / t_{1 / 2}^{\exp }$ & $t_{1 / 2}^{\text {new }} / t_{1 / 2}^{\exp }$ \\
\hline${ }_{84}^{208} \mathrm{Po}$ & 5.2155 & $0^{+}$ & $0^{+}$ & 0 & $2.898 \mathrm{y}$ & 14.9179 & $0.00127 \mathrm{y}$ & $2.898 \mathrm{y}$ & 0.00044 & 1 \\
\hline${ }_{84}^{210} \mathrm{Po}$ & 5.4075 & $0^{+}$ & $0^{+}$ & 0 & $138.376 \mathrm{~d}$ & 15.5665 & $0.04502 \mathrm{~d}$ & $138.376 \mathrm{~d}$ & 0.00033 & 1 \\
\hline${ }_{86}^{210} \mathrm{Rn}$ & 6.1585 & $0^{+}$ & $0^{+}$ & 0 & $2.40 \mathrm{~h}$ & 9.23733 & $0.00002 \mathrm{~h}$ & $2.40 \mathrm{~h}$ & $6.76363 * 10^{-6}$ & 1 \\
\hline${ }_{86}^{212} \mathrm{Rn}$ & 6.3850 & $0^{+}$ & $0^{+}$ & 0 & $23.9 \mathrm{~m}$ & 10.1241 & $0.00019 \mathrm{~m}$ & $23.9001 \mathrm{~m}$ & $7.99647 * 10^{-6}$ & 1.00001 \\
\hline${ }_{86}^{218} \mathrm{Rn}$ & 7.2630 & $0^{+}$ & $0^{+}$ & 0 & $0.035 \mathrm{~s}$ & 6.5191 & $2.80143 * 10^{-8} \mathrm{~s}$ & $0.0350003 \mathrm{~s}$ & $8.00408 * 10^{-7}$ & 1 \\
\hline
\end{tabular}




\begin{tabular}{|c|c|c|c|c|c|c|c|c|c|c|}
\hline${ }_{Z}^{A} \mathbf{X}$ & $\mathbf{E}_{\alpha}(\mathbf{M e V})$ & $I_{i}^{\pi_{i}}$ & $I_{f}^{\pi_{f}}$ & $\ell_{\alpha}$ & $t_{1 / 2}^{\exp }$ & $\mathbf{U}_{0}(\mathbf{M e V})$ & $t_{1 / 2}^{\mathrm{wkb}}$ & $t_{1 / 2}^{\text {new }}$ & $t_{1 / 2}^{w k b} / t_{1 / 2}^{\exp }$ & $t_{1 / 2}^{\text {new }} / t_{1 / 2}^{\exp }$ \\
\hline${ }_{86}^{222} \mathrm{Rn}$ & 5.5903 & $0^{+}$ & $0^{+}$ & 0 & $3.8235 \mathrm{~d}$ & 6.23796 & $5.58953 * 10^{-6} \mathrm{~d}$ & $3.82352 \mathrm{~d}$ & $1.46189 * 10^{-6}$ & 1 \\
\hline${ }_{88}^{222} \mathrm{Ra}$ & 6.6810 & $0^{+}$ & $0^{+}$ & 0 & $38.00 \mathrm{~s}$ & 6.47861 & $0.00002 \mathrm{~s}$ & $38.0003 \mathrm{~s}$ & $6.04471 * 10^{-7}$ & 1.00001 \\
\hline${ }_{88}^{226} \mathrm{Ra}$ & 4.8706 & $0^{+}$ & $0^{+}$ & 0 & $1600 \mathrm{y}$ & 7.82299 & $0.03820 \mathrm{y}$ & $1600.01 \mathrm{y}$ & 0.00002 & 1 \\
\hline${ }_{90}^{228} \mathrm{Th}$ & 5.5201 & $0^{+}$ & $0^{+}$ & 0 & $1.9116 \mathrm{y}$ & 6.60806 & $3.28263 * 10^{-6} \mathrm{y}$ & $1.91161 \mathrm{y}$ & $1.71722 * 10^{-6}$ & 1 \\
\hline - ${ }_{90}^{230} \mathrm{Th}$ & 4.7700 & $0^{+}$ & $0^{+}$ & 0 & $75380 y$ & 8.52931 & $4.26836 \mathrm{y}$ & $75380.1 \mathrm{y}$ & 0.00006 & 1 \\
\hline${ }_{90}^{232} \mathrm{Th}$ & 4.0828 & $0^{+}$ & $0^{+}$ & 0 & $1.405 * 10^{10} \mathrm{y}$ & 32.1944 & $1.32064 * 10^{10} \mathrm{y}$ & $1.405 * 10^{10} \mathrm{y}$ & 0.939958 & 1 \\
\hline${ }_{92}^{234} \mathrm{U}$ & 4.8585 & $0^{+}$ & $0^{+}$ & 0 & $2.455 * 10^{5} \mathrm{y}$ & 9.03385 & $15.4531 \mathrm{y}$ & 245501 y & 0.00006 & 1 \\
\hline${ }_{92}^{236} \mathrm{U}$ & 4.5720 & $0^{+}$ & $0^{+}$ & 0 & $2.342 * 10^{7} \mathrm{y}$ & 11.0640 & $15236.5 \mathrm{y}$ & $2.342 * 10^{7} \mathrm{y}$ & 0.00065 & 1 \\
\hline${ }_{94}^{238} \mathrm{Pu}$ & 5.5932 & $0^{+}$ & $0^{+}$ & 0 & $87.7 \mathrm{y}$ & 7.59949 & $0.00024 \mathrm{y}$ & 87.7006 y & $2.77893 * 10^{-6}$ & 1.00001 \\
\hline${ }_{94}^{240} \mathrm{Pu}$ & 5.2558 & $0^{+}$ & $0^{+}$ & 0 & $6563 \mathrm{y}$ & 7.94937 & $0.05176 \mathrm{y}$ & $6563.01 \mathrm{y}$ & $7.88666 * 10^{-6}$ & 1 \\
\hline${ }_{94}^{242} \mathrm{Pu}$ & 4.9844 & $0^{+}$ & $0^{+}$ & 0 & $3.733 * 10^{5} \mathrm{y}$ & 9.13029 & $15.8691 \mathrm{y}$ & $373301 \mathrm{y}$ & 0.00004 & 1 \\
\hline${ }_{96}^{246} \mathrm{Cm}$ & 5.4748 & $0^{+}$ & $0^{+}$ & 0 & $4730 y$ & 8.71907 & $0.03677 \mathrm{y}$ & $4730.01 \mathrm{y}$ & $7.77422 * 10^{-6}$ & 1 \\
\hline${ }_{96}^{248} \mathrm{Cm}$ & 5.1617 & $0^{+}$ & $0^{+}$ & 0 & $3.40 * 10^{5} \mathrm{y}$ & 9.55924 & $11.0685 \mathrm{y}$ & $3.40 * 10^{5} \mathrm{y}$ & 0.00003 & 1 \\
\hline${ }_{98}^{252} \mathrm{Cf}$ & 6.2169 & $0^{+}$ & $0^{+}$ & 0 & $2.645 \mathrm{y}$ & 7.43747 & $1.57881 * 10^{-6} \mathrm{y}$ & $2.64501 \mathrm{y}$ & $5.96902 * 10^{-7}$ & 1.00001 \\
\hline${ }_{84}^{209} \mathrm{Po}$ & 4.9792 & $1 / 2^{-}$ & $5 / 2^{-}$ & 2 & $102 \mathrm{y}$ & 22.5544 & 0.61612 y & $102 \mathrm{y}$ & 0.00604 & 1 \\
\hline - ${ }_{84}^{211} \mathrm{Po}$ & 7.5945 & $9 / 2^{+}$ & $1 / 2^{-}$ & 5 & $0.516 \mathrm{~s}$ & 21.0244 & $0.00005 \mathrm{~s}$ & $0.516 \mathrm{~s}$ & 0.00010 & 1 \\
\hline${ }_{85}^{212} \mathrm{At}$ & 7.8289 & $1^{-}$ & $5^{+}$ & 5 & $0.314 \mathrm{~s}$ & 22.5232 & $0.00003 \mathrm{~s}$ & $0.314 \mathrm{~s}$ & 0.00010 & 1 \\
\hline${ }_{90}^{229} \mathrm{Th}$ & 5.1676 & $5 / 2^{+}$ & $1 / 2^{+}$ & 2 & $7340 y$ & 26.6808 & $58.4120 \mathrm{y}$ & $7340 y$ & 0.00796 & 1 \\
\hline${ }_{92}^{233} \mathrm{U}$ & 4.9086 & $5 / 2^{+}$ & $5 / 2^{+}$ & 2 & $1.592 * 10^{5} \mathrm{y}$ & 9.60678 & $13.0668 \mathrm{y}$ & $1.592 * 10^{5} \mathrm{y}$ & 0.00008 & 1 \\
\hline${ }_{93}^{237} \mathrm{~Np}$ & 4.9591 & $5 / 2^{+}$ & $3 / 2^{-}$ & 1 & $2.144 * 10^{6} \mathrm{y}$ & 30.2065 & $56218 \mathrm{y}$ & $2.144 * 10^{6} \mathrm{y}$ & 0.02622 & 1 \\
\hline${ }_{94}^{239} \mathrm{Pu}$ & 5.2445 & $1 / 2^{+}$ & $7 / 2^{-}$ & 3 & $24110 \mathrm{y}$ & 10.5922 & $1.35989 \mathrm{y}$ & $24110 y$ & 0.00006 & 1 \\
\hline${ }_{95}^{241} \mathrm{Am}$ & 5.6378 & $5 / 2^{-}$ & $5 / 2^{+}$ & 1 & $432.2 \mathrm{y}$ & 9.84752 & $0.00541 \mathrm{y}$ & $432.201 \mathrm{y}$ & 0.00001 & 1 \\
\hline${ }_{95}^{243} \mathrm{Am}$ & 5.4381 & $5 / 2^{-}$ & $5 / 2^{+}$ & 1 & $7370 y$ & 11.3398 & $0.35419 \mathrm{y}$ & $7370.01 \mathrm{y}$ & 0.00005 & 1 \\
\hline${ }_{97}^{247} \mathrm{Bk}$ & 5.8890 & $3 / 2^{-}$ & $5 / 2^{-}$ & 2 & $1380 \mathrm{y}$ & 18.0463 & $0.31843 \mathrm{y}$ & $1380 y$ & 0.00023 & 1 \\
\hline${ }_{98}^{251} \mathrm{Cf}$ & 6.1758 & $1 / 2^{+}$ & $9 / 2^{-}$ & 5 & 898 y & 26.8754 & $1.31507 \mathrm{y}$ & $898 \mathrm{y}$ & 0.00146 & 1 \\
\hline
\end{tabular}

Table 3. Comparison of the experimental half-life values and the results calculated using the new and WKB formulas with the harmonic oscillator type well potential for the parameter $R_{0}=1.22 \mathrm{fm}$.

\begin{tabular}{|c|c|c|c|c|c|c|c|c|c|c|}
\hline${ }_{\mathrm{Z}}^{\mathrm{A}} \mathbf{X}$ & $\mathrm{E}_{\alpha}(\mathrm{MeV})$ & $I_{i}^{\pi_{i}}$ & $I_{f}^{\pi_{f}}$ & $\ell_{\alpha}$ & $t_{1 / 2}^{\exp }$ & $\mathbf{U}_{\mathbf{0}}(\mathrm{MeV})$ & $t_{1 / 2}^{w k b}$ & $t_{1 / 2}^{\text {new }}$ & $t_{1 / 2}^{w k b} / t_{1 / 2}^{\exp }$ & $t_{1 / 2}^{\text {new }} / t_{1 / 2}^{\exp }$ \\
\hline${ }_{84}^{208} \mathrm{Po}$ & 5.2155 & $0^{+}$ & $0^{+}$ & 0 & $2.898 \mathrm{y}$ & 16.1149 & $0.00163 \mathrm{y}$ & $2.898 \mathrm{y}$ & 0.00056 & 1 \\
\hline${ }_{84}^{210} \mathrm{Po}$ & 5.4075 & $0^{+}$ & $0^{+}$ & 0 & $138.376 \mathrm{~d}$ & 16.8183 & $0.05718 \mathrm{~d}$ & $138.376 \mathrm{~d}$ & 0.00041 & 1 \\
\hline${ }_{86}^{210} \mathrm{Rn}$ & 6.1585 & $0^{+}$ & $0^{+}$ & 0 & $2.40 \mathrm{~h}$ & 9.65884 & $0.00002 \mathrm{~h}$ & $2.40 \mathrm{~h}$ & $7.8447 * 10^{-6}$ & 1 \\
\hline${ }_{86}^{212} \mathrm{Rn}$ & 6.3850 & $0^{+}$ & $0^{+}$ & 0 & $23.9 \mathrm{~m}$ & 10.6042 & $0.00022 \mathrm{~m}$ & $23.9001 \mathrm{~m}$ & $9.26232 * 10^{-6}$ & 1 \\
\hline${ }_{86}^{218} \mathrm{Rn}$ & 7.2630 & $0^{+}$ & $0^{+}$ & 0 & $0.035 \mathrm{~s}$ & 6.73448 & $3.06062 * 10^{-8} \mathrm{~s}$ & $0.0350003 \mathrm{~s}$ & $8.74664 * 10^{-7}$ & 1.00001 \\
\hline${ }_{86}^{222} \mathrm{Rn}$ & 5.5903 & $0^{+}$ & $0^{+}$ & 0 & $3.8235 \mathrm{~d}$ & 6.4726 & $6.39451 * 10^{-6} \mathrm{~d}$ & $3.82352 \mathrm{~d}$ & $1.67242 * 10^{-6}$ & 1.00001 \\
\hline${ }_{88}^{222} \mathrm{Ra}$ & 6.6810 & $0^{+}$ & $0^{+}$ & 0 & $38.00 \mathrm{~s}$ & 6.70216 & $0.00003 \mathrm{~s}$ & $38.0003 \mathrm{~s}$ & $6.72179 * 10^{-7}$ & 1.00001 \\
\hline${ }_{88}^{226} \mathrm{Ra}$ & 4.8706 & $0^{+}$ & $0^{+}$ & 0 & $1600 \mathrm{y}$ & 8.20157 & $0.04662 \mathrm{y}$ & $1600 y$ & 0.00003 & 1 \\
\hline${ }_{90}^{228} \mathrm{Th}$ & 5.5201 & $0^{+}$ & $0^{+}$ & 0 & $1.9116 \mathrm{y}$ & 6.8677 & $3.81955^{*} 10^{-6} \mathrm{y}$ & $1.91161 \mathrm{y}$ & $1.99809 * 10^{-6}$ & 1.00001 \\
\hline${ }_{90}^{230} \mathrm{Th}$ & 4.7700 & $0^{+}$ & $0^{+}$ & 0 & $75380 y$ & 8.97807 & $5.33862 \mathrm{y}$ & $75380.3 \mathrm{y}$ & 0.00008 & 1 \\
\hline${ }_{90}^{232} \mathrm{Th}$ & 4.0828 & $0^{+}$ & $0^{+}$ & 0 & $1.405 * 10^{10} \mathrm{y}$ & 50.9229 & $3.48334 * 10^{10} \mathrm{y}$ & $1.405 * 10^{10} \mathrm{y}$ & 2.47924 & 1 \\
\hline${ }_{92}^{234} \mathrm{U}$ & 4.8585 & $0^{+}$ & $0^{+}$ & 0 & $2.455 * 10^{5} \mathrm{y}$ & 9.52352 & 19.4874 y & $245501 \mathrm{y}$ & 0.00008 & 1 \\
\hline${ }_{92}^{236} \mathrm{U}$ & 4.5720 & $0^{+}$ & $0^{+}$ & 0 & $2.342 * 10^{7} y$ & 11.8220 & $20371 \mathrm{y}$ & $2.342 * 10^{7} y$ & 0.00087 & 1 \\
\hline${ }_{94}^{238} \mathrm{Pu}$ & 5.5932 & $0^{+}$ & $0^{+}$ & 0 & $87.7 \mathrm{y}$ & 7.92354 & $0.00029 \mathrm{y}$ & $87.7003 \mathrm{y}$ & $3.29958 * 10^{-6}$ & 1 \\
\hline${ }_{94}^{240} \mathrm{Pu}$ & 5.2558 & $0^{+}$ & $0^{+}$ & 0 & $6563 \mathrm{y}$ & 8.31556 & $0.06286 \mathrm{y}$ & $6563 \mathrm{y}$ & $9.57858 * 10^{-6}$ & 1 \\
\hline${ }_{94}^{242} \mathrm{Pu}$ & 4.9844 & $0^{+}$ & $0^{+}$ & 0 & $3.733 * 10^{5} y$ & 9.6180 & $19.9753 \mathrm{y}$ & $373301 \mathrm{y}$ & 0.00005 & 1 \\
\hline${ }_{96}^{246} \mathrm{Cm}$ & 5.4748 & $0^{+}$ & $0^{+}$ & 0 & $4730 \mathrm{y}$ & 9.13514 & $0.04485 \mathrm{y}$ & $4730 y$ & $9.48227 * 10^{-6}$ & 1 \\
\hline${ }_{96}^{248} \mathrm{Cm}$ & 5.1617 & $0^{+}$ & $0^{+}$ & 0 & $3.40 * 10^{5} \mathrm{y}$ & 10.0730 & $13.9342 \mathrm{y}$ & $3.40 * 10^{5} \mathrm{y}$ & 0.00004 & 1 \\
\hline${ }_{98}^{252} \mathrm{Cf}$ & 6.2169 & $0^{+}$ & $0^{+}$ & 0 & $2.645 \mathrm{y}$ & 7.72806 & $1.83639 * 10^{-6} \mathrm{y}$ & $2.645 \mathrm{y}$ & $6.94287 * 10^{-7}$ & 1 \\
\hline${ }_{84}^{209} \mathrm{Po}$ & 4.9792 & $1 / 2^{-}$ & $5 / 2^{-}$ & 2 & $102 y$ & 25.4692 & $0.85586 \mathrm{y}$ & $102 \mathrm{y}$ & 0.00839 & 1 \\
\hline${ }_{84}^{211} \mathrm{Po}$ & 7.5945 & $9 / 2^{+}$ & $1 / 2^{-}$ & 5 & $0.516 \mathrm{~s}$ & 22.0306 & $0.00006 \mathrm{~s}$ & $0.516001 \mathrm{~s}$ & 0.00011 & 1 \\
\hline${ }_{85}^{212} \mathrm{At}$ & 7.8289 & $1^{-}$ & $5^{+}$ & 5 & $0.314 \mathrm{~s}$ & 23.7771 & $0.00003 \mathrm{~s}$ & $0.314 \mathrm{~s}$ & 0.00011 & 1 \\
\hline${ }_{90}^{229} \mathrm{Th}$ & 5.1676 & $5 / 2^{+}$ & $1 / 2^{+}$ & 2 & $7340 \mathrm{y}$ & 30.8213 & $84.5910 \mathrm{y}$ & $7340 y$ & 0.01152 & 1 \\
\hline${ }_{92}^{233} \mathrm{U}$ & 4.9086 & $5 / 2^{+}$ & $5 / 2^{+}$ & 2 & $1.592 * 10^{5} \mathrm{y}$ & 10.0846 & $16.2122 \mathrm{y}$ & $1.592 * 10^{5} \mathrm{y}$ & 0.00010 & 1 \\
\hline${ }_{93}^{237} \mathrm{~Np}$ & 4.9591 & $5 / 2^{+}$ & $3 / 2^{-}$ & 1 & $2.144 * 10^{6} y$ & 36.7733 & $90440.2 \mathrm{y}$ & $2.144 * 10^{6} y$ & 0.04218 & 1 \\
\hline${ }_{94}^{239} \mathrm{Pu}$ & 5.2445 & $1 / 2^{+}$ & $7 / 2^{-}$ & 3 & $24110 \mathrm{y}$ & 11.0755 & $1.65331 \mathrm{y}$ & $24110 y$ & 0.00007 & 1 \\
\hline${ }_{95}^{241} \mathrm{Am}$ & 5.6378 & $5 / 2^{-}$ & $5 / 2^{+}$ & 1 & $432.2 \mathrm{y}$ & 10.3320 & $0.00658 \mathrm{y}$ & $432.2 \mathrm{y}$ & 0.00002 & 1 \\
\hline${ }_{95}^{243} \mathrm{Am}$ & 5.4381 & $5 / 2^{-}$ & $5 / 2^{+}$ & 1 & $7370 y$ & 11.9873 & $0.44434 \mathrm{y}$ & $7370 y$ & 0.00006 & 1 \\
\hline${ }_{97}^{247} \mathrm{Bk}$ & 5.8890 & $3 / 2^{-}$ & $5 / 2^{-}$ & 2 & $1380 \mathrm{y}$ & 19.4567 & $0.41219 \mathrm{y}$ & $1380 \mathrm{y}$ & 0.00030 & 1 \\
\hline${ }_{98}^{251} \mathrm{Cf}$ & 6.1758 & $1 / 2^{+}$ & $9 / 2^{-}$ & 5 & $898 \mathrm{y}$ & 29.3742 & $1.69578 \mathrm{y}$ & $898.001 \mathrm{y}$ & 0.00189 & 1 \\
\hline
\end{tabular}

\section{Conclusion}

Here, the general transmission coefficient formula for a potential barrier with an arbitrary form has been easily calculated without making any approximation. In this calculation, the new method that we developed for the solution of the radial SE has been used. The transmission coefficient obtained from the new method is given by the formula (6). In this formula, it could be difficult to calculate 
analytically the integral $\int \sqrt{U_{2}(r)} d r$. If these calculations cannot be made analytically, they should then be performed by numerical calculation methods.

In the application of the general transmission coefficient formula to the $\alpha$-decay, three-dimensional harmonic oscillator potential well has been used. The results are given in the tables along with the experimental values. The tables also contain the "ratio" column for comparison. It can be seen in tables that the ratios for the all of the nuclei are equal to 1 (one) or close to 1 . The deviations from 1 are within the experimental error. Hence, it is said that the results obtained using the new formula are more realistic. In the WKB method, the wave function is sinusoidal before and after the potential barrier. However, it is not a sinusoidal but an exponential function in the potential barrier. So, the wave function inside the potential barrier is not sinusoidal; after the potential barrier, it becomes sinusoidal again. However in the new method, the wave functions are sinusoidal everywhere both inside and outsides of the potential barrier. But, the wave functions have different phases inside and outside the potential barrier and it advances everywhere as sinusoidal functions. This is more reasonable. It can also be said that it is more accurate and realistic. Besides, the WKB method gives an approximate wave function. In the new method, the wave function is exact because there is no approximation. That is why the theoretical calculated half-life values match better with the experimental values. From these, we conclude that the transmission coefficient given in Equation (6) is more correct and realistic. By using the new transmission coefficient and half-life formulas, the half-life values of nuclei can easily be calculated. The general transmission coefficient formula can be used for the other tunneling phenomenon such as the cold emission from the metals. We have also calculated this coefficient but we have not taken them in this article.

\section{Acknowledgements}

I would like to express my sincere gratitude to my wife Özel and my daughters Işı1 and Beril for their help in editing.

\section{References}

[1] H. H. Erbil, "A Simple solution of the time-independent Schrödinger equation in one dimension and some applications," in The International Review of Physics Vol. 1, 2007, 4, 197213.

[2] H. H. Erbil, "A Simple solution of the radial Schrödinger equation for spherically symmetric potentials and some applications," in The International Review of Physics Vol. 2, 2008, 1, 1-10.

[3] H. H. Erbil, "General solution of the Schrödinger equation with potential field quantization," in Turkish Journal of Physics, 42, 2018, 527-572.

[4] F. Schwabl, Quantum Mechanics, Translated by Ronald Kates, $2^{\text {nd }}$ ed.; Springer-Verlag, Berlin Heidelberg New York, USA, 1995.

[5] J. L. Powell and B. Crasemann, Quantum Mechanics, Addison-Wesley Publishing Company Inc., USA, 1965.

[6] L. D. Landau and E. M. Lifstits, Quantum Mechanics, Pergamon Press, 1958.

[7] J. Griffiths, Introductory Quantum Mechanics, Prentice Hall, 1994.

[8] H. H. Erbil, Analitik ve Kuantum Mekaniği, Nobel Akademik Yayıncilık, 2014, Ankara, Turkey.

[9] K. S. Krane, Introductory Nuclear Physics, John-Wiley \& Sons. 1988. Translated to Turkish by Başar Şarer, Palme Yayıncılık, Ankara, Turkey, 1988.

[10] S. Y. F Chu, L. P. Exström and R. B. Firestone, The Lund/LBNL Nuclear Data Search, Nucleardata.nuclear.lu.se/toi/index,asp, Summary drawings for $\mathrm{A}=1-277$. 